\title{
Efficient development of polymorphic microsatellite loci for Pteroceltis tatarinowii (UImaceae)
}

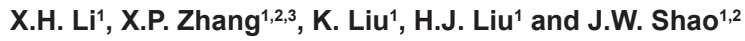 \\ ${ }^{1}$ College of Life Science, Anhui Normal University, Wuhu, China \\ ${ }^{2}$ The Key Laboratory of Conservation and Employment of Biological Resources of \\ Anhui, Wuhu, China \\ ${ }^{3}$ The Key Laboratory of Biotic Environment and Ecological Safety in Anhui \\ Province, Wuhu, China \\ Corresponding author: X.P. Zhang \\ E-mail: pinghengxu@sina.com.cn
}

Genet. Mol. Res. 14 (4): 16444-16449 (2015)

Received August 16, 2015

Accepted October 11, 2015

Published December 9, 2015

DOI http://dx.doi.org/10.4238/2015.December.9.15

\begin{abstract}
Pteroceltis tatarinowii (Ulmaceae) is a scientifically and economically important temperate deciduous tree that is endemic to China. In the present study, $12 P$. tatarinowii polymorphic microsatellite loci were developed using the tailed primer-M13-simple sequence repeats (TP-M13SSR) biotin-capture method. The number of alleles per locus ranged from 2 to 10 , with an average of 6.58 . The observed and expected heterozygosity ranged from 0.208 to 0.958 and from 0.198 to 0.858 , with average values of 0.703 and 0.710 , respectively. The markers isolated in this study represent a favorable tool for further analyses of the population genetic structure and evolutionary history of this relic tree.
\end{abstract}

Key words: Pteroceltis tatarinowii; Microsatellite; Population genetics; Conservation 


\section{INTRODUCTION}

Pteroceltis tatarinowii is a temperate deciduous tree endemic to China. The species belongs to the sole monotypic genus of Pteroceltis (Ulmaceae), and is also a tertiary relic plant. Hence, the species harbors important implications for delimiting systematic and paleontological puzzles. Because of its unique taxonomic status and fragmented distribution, it is considered a "rare endangered" species by the Red Data Book of Chinese Plants (Fu, 1992). P. tatarinowii is widely distributed across the mainland of China, and it characteristically grows on bare limestone mountains. The bark (phloem fiber) is the sole raw material for the manufacture of Chinese traditional Xuan paper (Fu, 1992; Cao, 1993), which has been listed in World Intangible Cultural Heritage. Moreover, due to strong endurance during drought and in poor soil, $P$. tatarinowii is an ideal mountain tree for water and soil maintenance in reconstructed vegetation, and it has been successfully employed in Shitai County of Anhui Province (Chen, 1994).

In our previous study, non-coding regions of the chloroplast genome and inter-simple sequence repeats(ISSR) in the nuclear genome were investigated to detect $P$. tatarinowii genetic diversity and population history (Li et al., 2012, 2013). Considering the discriminative limitation of cytoplasmic DNA inheritance and the dominant nature of inter-simple sequence repeats (ISSR), it is necessary to employ co-dominant markers to reappraise the genetic variation and phylogeographic patterns of this economic fiber tree. Therefore, the development of a suite of polymorphic microsatellite markers would utilize one of the most common and efficient measures currently used in molecular genetic analysis (Seino et al., 2014; Wang et al., 2015). Here, we used a modified biotin-capture with M13-tailed method (Schuelke, 2000) to isolate target microsatellite loci.

\section{MATERIAL AND METHODS}

Microsatellites were isolated from an enriched library that was constructed using a modified biotin-capture with a tailed M13 primer (Schuelke, 2000; Bloor et al., 2001; Zane et al., 2002). Using the modified CTAB (cetyltrimethylammonium bromide) protocol of Doyle (1991), total genomic DNA was extracted from silica-gel dried leaves of 72 individuals collected from Gansu $(\mathrm{N}=$ 24), Anhui ( $N=24)$, and Guangdong Province $(N=24)$ populations. Approximately $4 \mu \mathrm{g}$ mixed DNA of three individuals was digested with the Sau3A I restriction enzyme (TaKaRa, Dalian, Liaoning, China). The obtained size fragments, ranging from 300 to $1000 \mathrm{bp}$, were then recovered from $1.5 \%$ agarose gels using a gel extraction column kit (TaKaRa). The retrieved and purified fragments were ligated to the corresponding adaptor pair of SauL A (5'-GGCCAGAGACCCCAAGCTTCG-3') and SauL B (5'-PO4-GAT CCGAAGCTTGGGGTCTCTGGCC-3') linkers (Hamilton et al., 1999). The ligated fragments were amplified using PCR with SauL A as a primer. The 400-1000 bp amplified fragments were recovered from $1.5 \%$ agarose gels using a gel column extraction kit (TaKaRa). To enrich the fragments harboring microsatellite repeats, the retrieved fragments were hybridized with 5-biotinylated $(A C)_{12} /(A G)_{12}$ oligonucleotide probes, and were then captured with streptavidincoated magnetic beads (Roche, Mannheim, Germany). The above microsatellite-enriched DNA fragments were PCR-amplified using SauL A as the primer. The PCR products were purified and subsequently ligated into the plasmid PMD-19T vector (TaKaRa), and were then transformed into DH5a competent cells. Transformed cells grew at $37^{\circ} \mathrm{C}$ for $8 \mathrm{~h}$ on LB/ampicillin/IPTG/X-gal plates for blue and white selection. Positive colonies yielding two or more bands were screened for the 
presence of microsatellite motifs via PCR using SauL $A$ and $(A C)_{12}$ or $(A G)_{12}$ oligonucleotides as primers (Wu et al., 2008). In total, 152 positive clones were selected and sequenced on an automated $A B I 3700$ DNA sequencer. Seventy-two primer pairs were designed using Primer Premier 5.0 software (http://www.pre-mierbiosoft.com/), and 19 primers sets that yielded consistent and specific targeted products were chosen for subsequent allelic polymorphism testing in 72 individuals from the three populations. Nested PCR reactions were performed using single tube reactions with three oligos (oligo1: Foreword SSR primer with M13 at the 5'-end; oligo2: Reverse SSR primer; oligo3: universal fluorescent tag (FAM, HEX, TAMRA) labeled M13 primer (note that M13 primers were synthesized following the original published 5'-TGT AAA ACG ACG GCC AGT-3' sequence) (Schuelke, 2000). The PCR reactions were performed in $15 \mu \mathrm{L}$ mixture volumes containing $1.5 \mu \mathrm{L}$ 10X buffer ( $\mathrm{Mg}^{2+}$ free), 2.5 mmol dNTP mixture, 30-50 ng DNA, $0.4 \mu \mathrm{mol}$ oligo1 and oligo2, $0.1 \mu \mathrm{mol}$ oligo3, 0.5 units Taq DNA polymerase (TaKaRa), and $1.2 \mu \mathrm{L} 25 \mu \mathrm{mol} \mathrm{MgCl}_{2}$. The PCR conditions were $5 \mathrm{~min}$ at $94^{\circ} \mathrm{C}$ for initial denaturizing followed by 27 cycles of $30 \mathrm{~s}$ at $94^{\circ} \mathrm{C}, 30 \mathrm{~s}$ at optimized annealing temperatures (Table 1), and $30 \mathrm{~s}$ at $72^{\circ} \mathrm{C}$. The procedure was then switched to 10 cycles of $30 \mathrm{~s}$ at $94^{\circ} \mathrm{C}, 30 \mathrm{~s}$ at $53^{\circ} \mathrm{C}$, and $30 \mathrm{~s}$ at $72^{\circ} \mathrm{C}$, with a final extension time of $8 \mathrm{~min}$ at $72^{\circ} \mathrm{C}$. PCR products were screened and identified on $1.5 \%$ agarose gels, and the final PCR product was sent to the Crystal Biological Technology Co., LTD. (Shanghai) for genotyping.

Tests of significant deviation from Hardy-Weinberg equilibrium (HWE) and linkage disequilibrium (LD) were conducted using GENEPOP version 3.4 (Raymond and Rousset, 1995). Micro-Checker version 2.2.3 was used to determine null alleles (van Oosterhout et al., 2004). Cervus 2.0 software (Belkhir et al., 1996) was selected to identify the number of alleles per locus $\left(N_{A}\right)$, observed and expected heterozygosity per locus $\left(H_{O} / H_{E}\right)$, and polymorphic information content (PIC). The significance values for all tests were corrected using the sequential Bonferroni procedure (Rice, 1989).

\section{RESULTS}

In total, 19 microsatellite loci were identified, and 12 of these (PTTA8, PTTA9, PTTA11, PTTA12, PTTA16, PTTA17, PTTA31, PTTA37, PTTA42b, PTTA45b, PTTA53, and PTTA60) were sufficiently polymorphic and stable for amplification of the $72 P$. tatarinowii individuals collected from the three populations. The remaining seven loci (PTTA18b, PTTA26, PTTA42, PTTA46, PTTA65r, PTTA78, and PTTA91) may be useful in other populations (Table 1). The number of alleles per locus ranged from 2 to 10 , with an average of 6.58 , which is indicative of high allelic diversity. The observed and expected heterozygosity values varied from 0.208 to 0.958 and from 0.198 to 0.858 , with averages of 0.703 and 0.710 , respectively. The PIC values for individual loci ranged from 0.187 to 0.823 with an average of 0.655 . Of the 12 loci, no significant deviations from Hardy-Weinberg equilibrium(HWE) were detected by the Bonferroni adjustment with $\mathrm{P}<0.0042$ (Table 2), including a heterozygote deficit. Across the three populations, significant linkage disequilibrium was not detected between any pair of loci. However, some pairs displayed linkage in a single population (Gansu population: PTTA45 and PTTA53; Guangdong population: PTTA8 and PTTA9; PTTA9 and PTTA31). The null alleles were present at loci PTTA17 and PTTA31 in the Gansu population and at PTTA11 in the Guangdong population. Hence, rather than allelic sites, the respective linkage disequilibrium may be attributed to null alleles and small population effects. 
Table 1. Characteristics of 19 microsatellite primers developed in Pteroceltis tatarinowii.

\begin{tabular}{|c|c|c|c|c|c|}
\hline Primer & Primer sequence $\left(5^{\prime}-3^{\prime}\right)$ & Repeat motif & $\mathrm{Ta}\left({ }^{\circ} \mathrm{C}\right)$ & Size range $(b p)$ & Accession No. \\
\hline \multirow[t]{2}{*}{ PTTA8* } & F: САТАТТТССТСТТССССТАА & & & & \\
\hline & R: ACAGCTCACCCATACCTTC & (CT)12A (TCT)5 & 55 & $219-243$ & KR005831 \\
\hline \multirow[t]{2}{*}{ PTTA9* } & F: CACСTTTGCTTACTCССТG & & & & \\
\hline & R: AATGTACTCGCTAATGAACC & $(\mathrm{GA}) 13 \ldots(\mathrm{GT}) 8$ & 56 & $203-241$ & KR005832 \\
\hline \multirow[t]{2}{*}{ PTTA11* } & F: AGCGACTGAGGGTTTCATG & & & & \\
\hline & R: GCTTCTGCTCCGCCTTTCT & $(\mathrm{GA}) 5 \ldots(\mathrm{AG}) 13 \ldots(\mathrm{GT}) 8$ & 62 & $245-269$ & KR005833 \\
\hline \multirow[t]{2}{*}{ PTTA12* } & F: CAGGGCACTCCAATAGAATAG & & & & \\
\hline & R: ATGGTGCTGGGATGGGAAG & $(\mathrm{AG}) 13$ & 60 & $251-273$ & KR005834 \\
\hline \multirow[t]{2}{*}{ PTTA16* } & F: CATTTGGATACACCAGGAAGG & & & & \\
\hline & R: CAGCCATTGATGCTTAGTCC & (CT)11 & 60 & $165-185$ & KR005835 \\
\hline \multirow[t]{2}{*}{ PTTA17* } & F: TCTAGGCTGTATAAAGGGAC & & & & \\
\hline & R: GATGAAGTAAATGGGGAATC & (TC) $5 \ldots$ (TC) $12 \ldots$ (TC) 12 & 54 & $221-249$ & KR005836 \\
\hline \multirow[t]{2}{*}{ PTTA31* } & F: CATGTCACCATTACCGAAC & & & & \\
\hline & R: ACACAGTAAGAAAACACACC & (TC)19 & 55 & $140-166$ & KR005837 \\
\hline \multirow[t]{2}{*}{ PTTA37* } & F: TGGCGATGTGAAGCCCTAAG & & & & \\
\hline & R: TCATTTCAACGGTCAAGATTAC & $(A G) 10$ & 56 & $259-279$ & KR005838 \\
\hline \multirow[t]{2}{*}{ PTTA42b* } & F: CAATAATAGCCTTGCATCTC & & & & \\
\hline & R: CTCССTTTGAACAAAССТC & (TG)6 ...(TG)10 & 56 & $279-317$ & KR005839 \\
\hline \multirow[t]{2}{*}{ PTTA45b* } & F: CCTGTCCAGCTACTAATTTG & & & & \\
\hline & R: GTCTGCGATGGTATCTGTT & (AT)6(GT)18 & 56 & $176-190$ & KR005840 \\
\hline \multirow[t]{2}{*}{ PTTA53* } & F: CAGGTCCAGAGGGAGAAAC & & & & \\
\hline & R: CCCAGGGTCAAATAGGTAAT & $(\mathrm{AG}) 12$ & 60 & $288-312$ & KR005841 \\
\hline \multirow[t]{2}{*}{ PTTA60* } & F: GCTTCCTTGGGTCTCATCC & & & & \\
\hline & R: TCCACAGACGAGTAGTTCTCC & $(\mathrm{GA}) 9 \ldots(\mathrm{AG}) 6$ & 56 & $343-373$ & KR005842 \\
\hline \multirow[t]{2}{*}{ PTTA18b } & F: GCGGTGATTAGAAACTTGTAC & & & & \\
\hline & R: GCACATTTAGCCATTTTCAC & (TG)12 & 56 & $186-196$ & NO \\
\hline \multirow[t]{2}{*}{ PTTA26 } & F: GCGAAGCATTCTGAGGTAC & & & & \\
\hline & R: CTGGTATTGTCTCCATCGTC & $(\mathrm{TG}) 9$ & 57 & $217-231$ & NO \\
\hline \multirow[t]{2}{*}{ PTTA42 } & F: CTAACCAAAGTGCTGTTTGAG & & & & \\
\hline & R: СТTTCTCAССССАТССТААT & $(\mathrm{CT}) 7 \ldots(\mathrm{CA}) 9(\mathrm{AAAC}) 5$ & 56 & $197-215$ & NO \\
\hline \multirow[t]{2}{*}{ PTTA46 } & F: TCTCССТTCСАТGСАСАAT & & & & \\
\hline & R: AGTGCTTGTGGTTGTAGCG & (CT)12 & 53 & $136-152$ & NO \\
\hline \multirow[t]{2}{*}{ PTTA65r } & F: CATCTTAACTGTGGCACTAC & & & & \\
\hline & R: GTCTATGGTGGAGATGAAC & $(\mathrm{AC}) 22$ & 56 & $239-269$ & NO \\
\hline \multirow[t]{2}{*}{ PTTA78 } & F: ACCTACGCAGAATAATCGC & & & & \\
\hline & R: GATAACTTCACGGTTCCAG & (GA)12 & 56 & $126-158$ & NO \\
\hline \multirow[t]{2}{*}{ PTTA91 } & F: TGACCCATTAAGATGTGGTGG & & & & \\
\hline & R: GTGGCCCTTGACTTTGTGG & $(A C) 8$ & 57 & $262-288$ & NO \\
\hline
\end{tabular}

The details of repeat motifs, forward (F) and reverse (R) primer sequences, optimal temperatures $\left(T_{\mathrm{A}}\right)$, and allele size ranges are given. The asterisk $\left(^{*}\right)$ represents the polymorphic and stable primers chosen for further population genetic analyses. "NO" represents primers without accession numbers.

Table 2. Results of initial screening of three Pteroceltis tatarinowii populations.

\begin{tabular}{|c|c|c|c|c|c|c|c|c|c|c|c|c|}
\hline \multirow[b]{2}{*}{ Locus } & \multicolumn{4}{|c|}{ 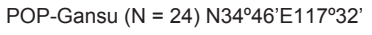 } & \multicolumn{4}{|c|}{ POP-Anhui $(\mathrm{N}=24) \quad \mathrm{N} 24^{\circ} 47^{\prime} \mathrm{E} 104^{\circ} 32^{\prime}$} & \multicolumn{4}{|c|}{ POP-Guangdong $(\mathrm{N}=24) \mathrm{N} 26^{\circ} 53^{\prime} \mathrm{E} 116^{\circ} 55^{\prime}$} \\
\hline & $N_{\mathrm{A}}$ & $H_{\mathrm{E}}$ & $H_{0}$ & PIC & $N_{\mathrm{A}}$ & $H_{\mathrm{E}}$ & $H_{\circ}$ & $\mathrm{PIC}$ & $N_{\mathrm{A}}$ & $H_{\mathrm{E}}$ & $H_{0}$ & $\mathrm{PIC}$ \\
\hline PTTA8 & 6 & 0.780 & 0.792 & 0.727 & 6 & 0.793 & 0.708 & 0.746 & 7 & 0.766 & 0.833 & 0.711 \\
\hline PTTA9 & 8 & 0.751 & 0.833 & 0.704 & 8 & 0.732 & 0.708 & 0.683 & 6 & 0.622 & 0.750 & 0.574 \\
\hline PTTA11 & 5 & 0.777 & 0.917 & 0.719 & 7 & 0.802 & 0.792 & 0.758 & 6 & 0.582 & 0.333 & 0.509 \\
\hline PTTA12 & 8 & 0.584 & 0.542 & 0.512 & 7 & 0.807 & 0.875 & 0.760 & 4 & 0.741 & 0.708 & 0.677 \\
\hline PTTA16 & 7 & 0.785 & 0.875 & 0.733 & 6 & 0.803 & 0.750 & 0.754 & 5 & 0.704 & 0.542 & 0.634 \\
\hline PTTA17 & 8 & 0.730 & 0.500 & 0.668 & 5 & 0.501 & 0.542 & 0.432 & 4 & 0.198 & 0.208 & 0.187 \\
\hline РТTA31 & 10 & 0.778 & 0.583 & 0.733 & 7 & 0.781 & 0.875 & 0.730 & 8 & 0.839 & 0.917 & 0.797 \\
\hline PTTA37 & 7 & 0.677 & 0.583 & 0.612 & 2 & 0.422 & 0.333 & 0.328 & 5 & 0.666 & 0.750 & 0.586 \\
\hline PTTA42b & 9 & 0.825 & 0.750 & 0.788 & 10 & 0.858 & 0.875 & 0.823 & 8 & 0.846 & 0.792 & 0.805 \\
\hline PTTA45b & 3 & 0.675 & 0.625 & 0.587 & 5 & 0.692 & 0.708 & 0.618 & 3 & 0.441 & 0.542 & 0.392 \\
\hline PTTA53 & 9 & 0.804 & 0.708 & 0.760 & 7 & 0.771 & 0.750 & 0.716 & 6 & 0.725 & 0.792 & 0.657 \\
\hline PTTA60 & 10 & 0.723 & 0.667 & 0.676 & 9 & 0.826 & 0.958 & 0.784 & 6 & 0.759 & 0.875 & 0.706 \\
\hline
\end{tabular}

Locus name, number of alleles per locus (NA), mean values of observed and expected heterozygosity $\left(H_{0}\right.$ and $\left.H_{E}\right)$, polymorphism information content (PIC), and $P$ values for Hardy-Weinberg equilibrium via Bonferroni correction are shown below $(P<0.0042)$. Sample size $(N)$ for each population is shown in parentheses, followed by the geographic coordinates of each sampled location. 


\section{DISCUSSION}

In this study, we isolated and identified $12 P$. tatarinowii polymorphic microsatellite sites with successful target products ranging from 126 to $373 \mathrm{bp}$ using TP-M13-SSR biotin-capture method. Through the pre-screening of 72 different individuals from three far apart populations, these markers exhibited favorable stability and high degrees of polymorphism with an average of 6.58 alleles per marker. In addition, no significant departure from HWE was found among all the three populations.

$P$. tatarinowii is a relic and monogeneric tree endemic to China, indicative of limestone habitat. Considering the unique systematic status and economic values of the rare species, our research group had conducted continuously molecular surveys with the focus of detecting the species' population genetic diversity and tracing its evolutionary demography using non-coding regions of the chloroplast genome and ISSR markers (Li et al., 2012; Li et al., 2013). The two markers both detected still high genetic diversity harbored by this relic tree. However, the cpDNA data revealed that South China was the main refugia for $P$. tatarinowii, and a post-glacial reclonization occurred in North China, which were not supported by the data based on ISSR analysis of $P$. tatarinowii. In order to further illuminate this confusion, we need more evidences especially from nuclear genome, which is dominated by seed flow and pollen flow and exhibits more genetic variability. With the advantages of co-dominance, high polymorphism, well reliability and abundant genomic information, microsatellite sites have been extensively used in the genetics and evolutionary studies (Provan et al., 2001; Wang et al., 2015). Herein, these 12 polymorphic microsatellite loci appear to be highly informative and are can be utilized as powerful tools to detect genetic diversity, gene flow, population evolutionary relationship and parental analysis of $P$. tatarinowii, which would further reveal the population evolutionary history of the tree, contribute understanding of deciduous trees vegetation succession in mainland of China, and aid the development of conservation and management measures for the relic, economic tree.

\section{Conflicts of interest}

The authors declare no conflict of interest.

\section{ACKNOWLEDGMENTS}

Research supported by the National Science Foundation of China (\#30970292 and \#41401062), the Anhui Provincial Natural Science Foundation of China (\#1508085MD66), the Innovation Funds of Anhui Normal University (\#2013cxjj15), the Doctor Initial Funding of Anhui Normal University, the State Key Laboratory of Palaeobiology and Stratigraphy (Nanjing Institute of Geology and Palaeontology, CAS, \#143115) , and the Central Department Budget Funds For 2012 (\#2130211).We thank Dr. Zhang Li for her field collection work.

\section{REFERENCES}

Belkhir K, Borsa P, Goudet J and Bonhomme F (1996). GENETIX: Logiciel sous Windows pour la Génétique de Population. Laboatoire Génome et Populations. CNRS UMR 5000: 1996-2004.

Bloor PA, Barker FS, Watts PC, Noyes HA, et al. (2001). Microsatellite libraries by enrichment Version 1.0. Animal Genomics Laboratory, School of Biological Sciences. University of Liverpool, United Kingdom.

Cao TS (1993). Xuan paper of China. CHLIP Beijing 20-34. 
Chen DG (1994). Pteroceltis tatarinowii. Soil Water Conserve. Sinica 11: 36.

Doyle JJ (1991). DNA protocols for plants: CTAB total DNA isolation. In: Molecular techniques in taxonomy (Hewitt GM and Johnston A, eds.). Springer-Verlag, Berlin, 283-293.

Fu LG (1992). Red data book of Chinese plants-rare and endangered plants (Volume 1). Science Press, Beijing.

Hamilton MB, Pincus EL, Di Fiore A and Flesher RC (1999). Universal linker and ligation procedures for construction of genomic DNA libraries enriched for microsatellites. BioTechniques 27: 500-507.

Li XH, Shao JW, Lu C, Zhang XP, et al. (2012). Chloroplast phylogeography of a temperate tree Pteroceltis tatarinowii (Ulmaceae) in China. J. Syst. Evol. 50: 325-333.

Li XH, Zhang H, Wang DY, Zhang L, et al. (2013). The genetic structure of endemic plant Pteroceltis tatarinowii by ISSR markers. Acta Ecol. Sinica 33: 4892-4901.

Provan J, Powell W and Hollingsworth PM (2001). Chloroplast microstellites: new tools for studies in plant ecology and evolution. Trends Ecol. Evol. 16: 142-147.

Raymond M and Rousset F (1995). GENEPOP: population genetics software for extract tests and edumenicism. J. Hered. 86: 248-249.

Rice WR (1989). Analyzing tables of statistical tests. Evolution 223-225.

Schuelke M (2000). An economic method for the fluorescent labeling of PCR fragments. Nat. Biotechnol. 18: 233-234.

Seino MM, Vega Cd, Bazaga P, Jacquemyn H, et al. (2014). Development and characterization of microsatellite loci for the primrose Primula vulgaris and successful cross-amplification in the congeneric $P$. elatior and $P$. veris. Conserv. Genet. Resour. 6: 653-655.

Van Oosterhout C, Huthinson WF, Wills DPM and Shipley P (2004). Micro-checker software for identifying and correcting genotyping errors in microsatellite data. Mol. Ecol. Notes 4: 535-538.

Wu HL, Meng K and Zhu GP (2008). Isolation and characterization of microsatellite markers in black muntjac (Muntiacus crinifrons). Mol. Ecol. Resour. 8: 584-586.

Wang YH, Jiang WM, Comes HP, Hu FS, et al. (2015). Molecular phylogeography and ecological niche modeling of a widespread herbaceous climber, Tetrastigma hemsleyanum (Vitaceae): insights into Plio-Plerstocene range dynamics of evergreen forest in subtropical China. New Phytol. 206: 852-867.

Zane L, Bargelloni L and Patarnello T (2002). Strategies for microsatellite isolation: a review. Mol. Ecol. 11: 1-16. 